\title{
Molecular epidemiology and genetic diversity of duck hepatitis A virus type 3 in Shandong province of China, 2012-2014
}

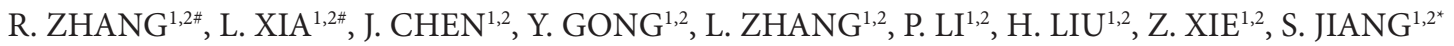

${ }^{1}$ Department of Preventive Veterinary Medicine, College of Veterinary Medicine, Shandong Agricultural University, Shandong Taian, 271018, P. R. China; ${ }^{2}$ Shandong Provincial Key Laboratory of Animal Biotechnology and Disease Control and Prevention, Shandong Taian, 271018, P. R. China

Received September 30, 2016; revised November 21, 2016; accepted October 13, 2017

\begin{abstract}
Summary. - The infections with duck hepatitis A virus type 3 (DHAV-3) become common in eastern Asia. To better understand the molecular evolution and genetic variation of DHAV-3, a total of 482 dead Cherry Valley duckling liver samples collected from Shandong province of China during 2012-2014 were tested, and the complete P1 coding sequences of 18 DHAV-3 strains were analyzed. The detection rate of DHAV-3 was $64.5 \%$ (311/482) in clinical liver samples and 73.0\% (92/126) in duckling flocks. The P1 genes of the 18 DHAV-3 isolates shared $91.9 \%-99.0 \%$ nucleotide similarity and $95.2 \%-100 \%$ amino acid similarity with those of the other 26 reference strains. Based on the P1 and VP1 gene sequences, phylogenetic analysis results indicated that the genotyping of DHAV-3 strains presented a distinct geographical distribution. Except B63 strain, all Chinese strains isolated from different host species (duck or goose) at different time were classed into the CH genotype. All Korean and Vietnamese strains belonged to the KV genotype, and all the Korean strains were clustered into KV1 subgenotype, while B63 strain and the Vietnamese strains from different host species (duck or goose) were clustered into KV2 subgenotype. Ten variable amino acid residues were highly conserved within genotypes or subgenotypes in the VP0, VP3 and VP1, respectively, which were possibly the geographic molecular markers of DHAV-3. To the best of our knowledge, this is the first study about the genetic variation of the P1 gene of different DHAV-3 strains, which will be helpful for understanding the molecular epidemiology of DHAV-3.
\end{abstract}

Keywords: duck hepatitis A virus type 3 (DHAV-3); P1 gene; VP1 gene; molecular epidemiology; geographical distribution

\section{Introduction}

Duck virus hepatitis (DVH), caused by duck hepatitis virus (DHV), is an acute, rapidly spreading, and fatal disease of young ducklings and has resulted in highly significant economic losses to the duck industry worldwide. DHV includes at least three different RNA viruses, duck hepatitis A virus

*Corresponding author. E-mail: sjjiang@sdau.edu.cn; phone: +86538-8245799. "Ruihua Zhang and Linlin Xia contributed equally to this work.

Abbreviations: $\mathrm{DVH}=$ duck virus hepatitis; $\mathrm{DHV}=$ duck hepatitis virus; $\mathrm{DHAV}=$ duck hepatitis $\mathrm{A}$ virus; $\mathrm{DAst} \mathrm{V}=$ duck astrovirus; $\mathrm{CH}$ genotype $=$ Chinese genotype $\mathrm{KV}$ genotype $=$ Korean and Vietnamese genotype
(DHAV), duck astrovirus type 1 (DAstV-1) and duck astrovirus type 2 (DAstV-2), and no antigenic relationships have been found among them (Toth, 1969; Haider and Calnek, 1979; Woolcock, 2003). DHAV s had been classified into three genotypes by phylogenetic analyses: the classical genotype 1 (DHAV-1) (Kim et al., 2006; Ding and Zhang, 2007; Tseng et al., 2007), the genotype only isolated in Taiwan (DHAV-2) (Tseng and Tsai, 2007), and the genotype firstly identified in South Korea (DHAV-3) (Kim et al., 2007). Based on the neutralization tests, DHAVs were divided into three serotypes corresponding to the three genotypes (Kim et al., 2007; Tseng and Tsai, 2007).

In our previous study, DHAV-1, DHVA-3 and DAstV-1 were detected from Shandong province of China (Chen et al., 2014). In recent years, the mixed infections of different 
DHAVs become common in eastern Asia (Tseng and Tsai, 2007; Chen et al., 2013; Soliman et al., 2015; Lin et al., 2016), causing disease prevention and control more challenging. As a new serotype of DHAV isolated in South Korea and China, DHAV-3 could cause an acute and fatal disease of ducklings (Kim et al., 2007; Fu et al., 2008; Xu et al., 2012).

As the only member of a novel genus Avihepatovirus in the family Picornaviridae, the complete genome of DHAV is comprised of a single-stranded positive-sense RNA of approximately 7,700 nucleotides excluding the poly(A) tail at the 3 ' end, encapsulated in an icosahedral structure, which is composed of the structural proteins VP0, VP3 and VP1 (Kim et al., 2006; Tseng and Tsai, 2007). These three structural proteins are the secondary cleavage products of a capsid precursor polyprotein (P1). According to the alignment of the capsid proteins of DHAV and other picornaviruses, several of the most variable regions are at the termini, particularly the $\mathrm{N}$-terminus of VP0 and the two termini of VP1 (Johansson et al., 2002; Ding and Zhang, 2007; Gao et al., 2012), which indicates that some conserved functions might be performed by different capsid proteins of DHAV.

In this study, using the multiplex RT-PCR assay developed in our previous work for diagnosing DHAV-1, DHVA-3 and DAstV-1 mixed infection (Chen et al., 2014), we detected 482 clinical dead ducking liver samples collected from Shandong province of China from 2012 to 2014. The complete P1 genes of 18 DHAV-3 strains isolated from different duckling flocks were selected for sequencing and analysis. This paper is the first study about the genetic variation of the $\mathrm{P} 1$ genes of different DHAV-3 strains, which will be helpful for understanding the molecular epidemiology of DHAV-3.

\section{Materials and Methods}

Clinical specimens and viruses. Liver samples from 482 dead Cherry Valley ducklings under 3 weeks old were obtained from 126 flocks in Shandong province of China between January of 2012 and December of 2014. The 126 flocks of ducklings were all not vaccinated with live DVH vaccine. The mortality of duck flocks was $20 \%-85 \%$, and the sick ducklings died quickly with typical hemorrhagic hepatitis. Eighteen DHAV-3 strains (named JN1206, JN1209, LY1304, LY1305, LY1402, LY1405, LY1408, LY1417, QZ1401, QZ1403, QZ1404, WF1203, WF1210, WF1240, YT1213, YT1220, ZQ1403 and ZQ1408) isolated from different duckling flocks were selected for sequencing and analysis of the complete P1 gene (Table 1).

Primers. According to our previous study (Chen et al., 2014), the primers for DHAV-1, DHVA-3 and DAstV-1 typing (DHAV-1F: 5'-GAT GTG GCA Y(T/C)GT TGT Y(T/C)AA Y(T/C)CG A- 3', DHAV-1R: 5'-CTG ATG TD(G/A/T)C CAG GR(A/G)A TTG GTC G-3', DHAV-3F: 5'-GAG CCA GAA TTG GAA TGG ACA CA-3', DHAV-3R: 5'-CAT ACT TR(G/A)C CAC CAA CTG CCA ATC-3',
DAstV-1F: 5'-ATG GCC CAG AGC GGT GAA AA-3' and DAstV-1R: 5'-GCC AGG TGT CAA CAA TCA TGC-3') were used to detect and distinguish the three DHVs. Based on the sequence alignments of all DHAV-3 sequences retrieved from GenBank (http://www.ncbi.nlm. nih.gov), two pairs of primers were selected to amplify the complete P1 gene. The first pair of primers (AF 5'-CAC ACT GCC TGA TAG GGT CG-3' and AR 5'-CTG GCT TCC AAA GGT CAA TAA-3') was designed to amplify a $1225 \mathrm{bp}$ fragment (nucleotides 586-1810 in the genome of DHAV-3), and the other pair of primers (BF 5'GAC CTT TGG AAG CCA GTT TA-3' and BR 5'-CAT CAC AGG CAC GAA CAA GT-3') was designed to amplify a 1517 bp fragment (nucleotides 1795-3311 in the genome of DHAV-3). All the primers were synthesized by Sangon (Shanghai, China).

Detection of clinical specimens. All the livers of the 482 dead ducklings were analyzed by the multiplex RT-PCR method according to the previous study (Chen et al., 2014). The viral RNA was extracted from the liver samples using the E.Z.N.A. ${ }^{\mathrm{TM}}$ Viral RNA Kit (Omega Bio-Tek, Doraville, USA) and reverse transcribed into cDNA using a RevertAidTM First Strand cDNA Synthesis Kit (Fermentas, Burlington, Canada) according to the manufacturer's instructions. Then, the cDNA was tested by the multiplex RT-PCR method for differential diagnosis for mixed infection of DHVA-1, DHVA-3 and DAstV-1.

RNA extraction and P1 sequencing. The DHAV-3 strains were propagated in the allantoic cavities of 10-day-old duck embryos for $72 \mathrm{~h}$ at $37^{\circ} \mathrm{C}$. The virus RNA was extracted from allantoic liquids of dead duck embryos. RT-PCR was then performed for amplification of selected $18 \mathrm{P} 1$ genes with the two pairs of primers. The RT-PCR conditions were $50^{\circ} \mathrm{C}$ for $30 \mathrm{~min}, 94^{\circ} \mathrm{C}$ for $2 \mathrm{~min}$, and then 32 cycles of $94^{\circ} \mathrm{C}$ for $30 \mathrm{~s}, 50^{\circ} \mathrm{C}$ for $35 \mathrm{~s}, 72^{\circ} \mathrm{C}$ for $1 \mathrm{~min}$, and with a final step of $72^{\circ} \mathrm{C}$ for $5 \mathrm{~min}$. PCR products were purified using a gel purification kit (CWBIO, China), and the purified PCR products were TA-cloned into the pMD18-T vector (TaKaRa, China) following the manufacturer's instructions, and then sent to a commercial service for sequencing (Shanghai Sangon Biological Engineering Technology \& Service Co., Ltd).

Sequence analysis. The $\mathrm{P} 1$ sequences of $26 \mathrm{DHAV}-3$ reference strains and the VP1 sequences of other 31 DHAV-3 reference strains were retrieved from GenBank (http://www.ncbi.nlm.nih.gov, Table 1). Multiple sequence alignment was analyzed using DNAStar Clustal W program (DNAStar Inc. Madison, WI, USA). Based on P1 and VP1 nucleotide sequences and amino acid sequences of the DHAV-3 strains, the phylogenetic trees were respectively constructed by MEGA 6.0 with Neighbor-joining method (Tamura et al., 2013).

\section{Results}

Detection of clinical specimens by the multiplex RT-PCR assay

In the 482 clinical samples, 103 samples were identified as co-infection with two of the three DHVs, while 379 samples 
Table 1. Summary of DHAV-3 strains used in this work

\begin{tabular}{|c|c|c|c|c|c|}
\hline Strain & Location & Year of isolation & $\begin{array}{c}\text { GenBank } \\
\text { Acc. No. }\end{array}$ & Host & Gene \\
\hline JN1206 & Shandong, China & 2012 & KP715480 & Duck & $\mathrm{P} 1$ \\
\hline JN1209 & Shandong, China & 2012 & KP715481 & Duck & $\mathrm{P} 1$ \\
\hline LY1304 & Shandong, China & 2013 & KP715482 & Duck & $\mathrm{P} 1$ \\
\hline LY1305 & Shandong, China & 2013 & KP715483 & Duck & $\mathrm{P} 1$ \\
\hline LY1402 & Shandong, China & 2014 & KP715484 & Duck & $\mathrm{P} 1$ \\
\hline LY1405 & Shandong, China & 2014 & KP715485 & Duck & $\mathrm{P} 1$ \\
\hline LY1408 & Shandong, China & 2014 & KP715486 & Duck & $\mathrm{P} 1$ \\
\hline LY1417 & Shandong, China & 2014 & KP715487 & Duck & $\mathrm{P} 1$ \\
\hline QZ1401 & Shandong, China & 2014 & KP715488 & Duck & $\mathrm{P} 1$ \\
\hline QZ1403 & Shandong, China & 2014 & KP715489 & Duck & $\mathrm{P} 1$ \\
\hline QZ1404 & Shandong, China & 2014 & KP715490 & Duck & $\mathrm{P} 1$ \\
\hline WF1203 & Shandong, China & 2012 & KP715491 & Duck & $\mathrm{P} 1$ \\
\hline WF1210 & Shandong, China & 2012 & KP715492 & Duck & $\mathrm{P} 1$ \\
\hline WF1240 & Shandong, China & 2012 & KP715493 & Duck & $\mathrm{P} 1$ \\
\hline YT1213 & Shandong, China & 2012 & KP715494 & Duck & $\mathrm{P} 1$ \\
\hline YT1220 & Shandong, China & 2012 & KP715495 & Duck & $\mathrm{P} 1$ \\
\hline ZQ1403 & Shandong, China & 2014 & KP715496 & Duck & $\mathrm{P} 1$ \\
\hline ZQ1408 & Shandong, China & 2014 & KР715497 & Duck & $\mathrm{P} 1$ \\
\hline G & Fujian, China & 1999 & EU755009 & Duck & $\mathrm{P} 1$ \\
\hline GD & Guangdong, China & 1999 & GQ122332 & Duck & $\mathrm{P} 1$ \\
\hline B63 & Beijing, China & 2008 & EU747874 & Duck & $\mathrm{P} 1$ \\
\hline FS & Guangdong, China & 2008 & EU877916 & Duck & $\mathrm{P} 1$ \\
\hline SD01 & Shandong, China & 2008 & GQ485310 & Duck & $\mathrm{P} 1$ \\
\hline $1 \mathrm{v}$ & Shandong, China & 2009 & GU250782 & Duck & $\mathrm{P} 1$ \\
\hline C-BLZ & Beijing, China & 2009 & GU066822 & Duck & $\mathrm{P} 1$ \\
\hline C-YCW & Beijing, China & 2009 & GU066824 & Duck & $\mathrm{P} 1$ \\
\hline C-YCZ & Beijing, China & 2009 & GU066823 & Duck & $\mathrm{P} 1$ \\
\hline C-YDF & Beijing, China & 2009 & GU066821 & Duck & $\mathrm{P} 1$ \\
\hline SD02 & Shandong, China & 2009 & GQ485311 & Duck & $\mathrm{P} 1$ \\
\hline C-GY & Guangdong, China & 2007 & EU352805 & Duck & $\mathrm{P} 1$ \\
\hline JS2010 & Jiangsu, China & 2010 & HQ654774 & Duck & $\mathrm{P} 1$ \\
\hline JT & Jilin, China & 2010 & JF835025 & Goose & $\mathrm{P} 1$ \\
\hline SD1101 & Shandong, China & 2010 & JQ409566 & Duck & $\mathrm{P} 1$ \\
\hline $\mathrm{B}-\mathrm{N}$ & Guangdong, China & 2011 & JX235698 & Duck & $\mathrm{P} 1$ \\
\hline SD1201 & Shandong, China & 2011 & KC993890 & Duck & $\mathrm{P} 1$ \\
\hline GX12-01 & Guangxi, China & 2012 & KC893553 & Duck & $\mathrm{P} 1$ \\
\hline EY & China & 2014 & KP995438 & Goose & $\mathrm{P} 1$ \\
\hline LS & China & 2014 & KP233203 & Duck & $\mathrm{P} 1$ \\
\hline AP-04114 & South Korea & $2003-2004$ & DQ812093 & Duck & $\mathrm{P} 1$ \\
\hline AP-03337 & South Korea & $2003-2004$ & DQ256132 & Duck & $\mathrm{P} 1$ \\
\hline AP-04009 & South Korea & $2003-2004$ & DQ256133 & Duck & $\mathrm{P} 1$ \\
\hline AP-04203 & South Korea & $2003-2004$ & DQ256134 & Duck & $\mathrm{P} 1$ \\
\hline D11-JW-018 & South Korea & 2011 & JX312194 & Duck & $\mathrm{P} 1$ \\
\hline DN2 & Vietnam & 2009 & JF914944 & Duck & $\mathrm{P} 1$ \\
\hline KH01 & Vietnam & 2012 & KM361879 & Duck & VP1 \\
\hline KH02 & Vietnam & 2012 & KM361880 & Duck & VP1 \\
\hline LA1 & Vietnam & 2011 & KM361881 & Goose & VP1 \\
\hline DN1 & Vietnam & 2009 & JF925120 & Duck & VP1 \\
\hline $\mathrm{NC}$ & Vietnam & 2009 & JF925121 & Duck & VP1 \\
\hline
\end{tabular}


Table 2. The results of the multiplex RT-PCR assay to detect infection in suspected positive clinical samples

\begin{tabular}{|c|c|c|c|c|}
\hline \multirow{2}{*}{ Infection } & \multicolumn{2}{|c|}{ Individual test results } & \multicolumn{2}{|c|}{ Group test results } \\
\hline & Positive number & Positive rate (\%) & Positive number & Positive rate (\%) \\
\hline DHAV-1 & 154 & 31.95 & 29 & 23.02 \\
\hline DHAV-3 & 217 & 46.97 & 43 & 34.13 \\
\hline DAstV-1 & 8 & 16.67 & 0 & 0 \\
\hline DHAV-1+DHAV-3 & 62 & 12.86 & 25 & 19.84 \\
\hline DHAV-1+DAstV-1 & 9 & 1.87 & 5 & 3.97 \\
\hline DHAV-3+DAstV-1 & 32 & 6.64 & 18 & 14.29 \\
\hline $\begin{array}{l}\text { DHAV-1+DHAV-3- } \\
+ \text { DAstV-1 }\end{array}$ & 0 & 0 & 6 & 4.76 \\
\hline Total & 482 & & 126 & \\
\hline
\end{tabular}

were detected as positive for only DHAV-1 (154), DHAV-3 (217) or DAstV-1 (8) (Table 2). There was no sample detected as DHAV-1, DHAV-3 and DAstV-1 co-infection. In the 126 duckling flocks, 6 (4.8\%) were identified as DHAV-1, DHAV-3 and DAstV-1 mixed infection, 48 (38.1\%) were identified as mixed infection with two of the three DHVs, 72 (57.1\%) were single infection with one of the three DHVs (Table 2).

\section{Sequence analysis of P1 gene and VP1 gene}

The P1 genes of selected 18 DHAV-3 isolates were successfully amplified by RT-PCR. P1 gene sequences of the 18 DHAV-3 strains were submitted into GenBank, and the Acc. Nos. were from KP715480 to KP715497 (Table 1). Further analysis indicated that all these P1 genes were 2199 bp long and encoded 733 amino acids, in which the VP0, VP3 and VP1 were coded by amino acids 1-256, 257-493 and 494733 , respectively. Multiple sequence alignment showed that the P1 gene sequences of the 18 strains determined in this study shared $95.9 \%-99.8 \%$ nucleotide sequence homology and $97.4 \%-100 \%$ amino acid sequence homology with each other, while they shared $91.9 \%-99.0 \%$ nucleotide similarity and $95.2 \%-100 \%$ amino acid similarity with those of the other 26 DHAV-3 reference strains. In multiple sequence alignment of VP1 protein, five other Vietnamese strains were added to the analysis (Table 1). The VP1 gene sequences of the 18 strains determined in our study shared $94.7 \%-100 \%$ nucleotide sequence homology and $96.2 \%-100 \%$ amino acid sequence homology with each other, while they shared $90.1 \%-100 \%$ nucleotide similarity and $90 \%-100 \%$ amino acid similarity with those of the other 31 reference strains.

As for P1 gene, the two DHAV-3 strains (JT strain and EY strain) isolated from geese shared 91.9\%-99.2\% nucleotide and $95.4 \%-100 \%$ amino acid sequence identities with the 42 strains isolated from ducks. Otherwise, for VP1 gene, the three DHAV-3 strains (JT, EY and LA1) isolated from geese shared $90.1 \%-99.6 \%$ nucleotide and $90.4 \%-100 \%$ amino acid sequence identities with the 46 strains isolated from ducks.
It indicated that the DHAV-3 strains isolated from different hosts shared high sequence identity, which was similar to the strains entirely isolated from ducks.

Comparative analysis showed that variations occurred throughout the entire $\mathrm{P} 1$ protein, and there was only one high variable region (HVR) located at the C-terminus (amino acid residues 178-219) of VP1, whereas a conserved QSD (Gln-Ser-Asp) motif (amino acids 197-199) existed in the HVR of all 49 DHAV-3 strains (Fig. 1).

\section{Phylogenetic analysis}

Based on the P1 nucleotide sequences and amino acid sequences, respectively, of the DHAV-3 strains, the phylogenetic trees were constructed (Fig. 2). All of the 44 strains were clustered into two distinct genotypes: all Chinese isolates except B63 strain were included in one genotype (Chinese genotype, $\mathrm{CH}$ genotype), while $\mathrm{B} 63$ strain, all the Korean and Vietnamese strains belonged to the other genotype (Korean and Vietnamese genotype, KV genotype). The P1 gene sequences of the 37 DHAV-3 strains in CH genotype shared $94.7 \%-99.8 \%$ nucleotide and $95.2 \%-100 \%$ amino acid sequence homology with each other (Table 3). All KV strains could be further divided into two subgenotypes (KV1 and KV2), and the P1 gene sequences of the DHAV-3 strains in KV genotype shared 93.4\%-99.3\% nucleotide and $97.0 \%-99.9 \%$ amino acid sequence homology with each other (Table 3). All Korean strains were clustered into KV1, while B63 strain and the Vietnamese strain DN2 were clustered into KV2. The P1 gene sequences of the DHAV-3 strains between $\mathrm{CH}$ and KV genotypes shared only 91.9\%-96.1\% nucleotide similarity and $95.2 \%-97.1 \%$ amino acid similarity with each other (Table 3 ).

Based on the VP1 nucleotide sequences and amino acid sequences of the DHAV-3 strains, the phylogenetic trees were constructed (Fig. 3). All of the 49 strains were also clustered into two distinct genotypes: all Chinese isolates except B63 strain were included in one genotype ( $\mathrm{CH}$ genotype), while B63 strain, all the Korean and Vietnamese strains 


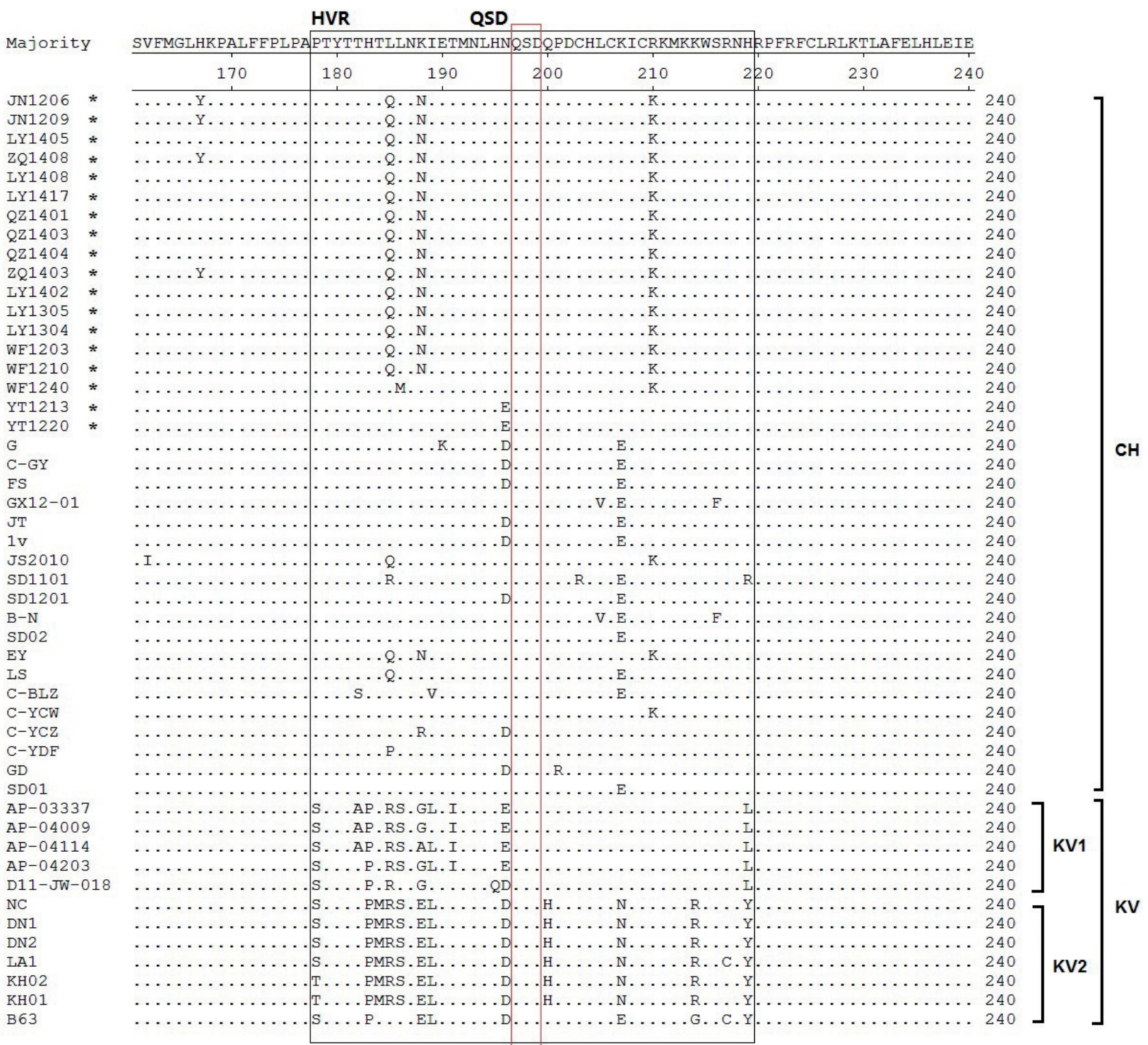

Fig. 1

Amino acids alignment based on VP1 proteins of 49 DHAV-3 strains

Isolates in this study were marked with asterisks $\left(^{*}\right)$. The high variable region (HVR) at the C-terminus of VP1 is shown in box and the QSD motif has been specifically marked.

belonged to the other genotype (KV genotype). The VP1 gene sequences of the $37 \mathrm{DHAV}-3$ strains in $\mathrm{CH}$ genotype shared $93.9 \%-100 \%$ nucleotide and $95.4 \%-100 \%$ amino acid sequence homology with each other (Table 4). Based on the VP1 nucleotide sequences and amino acid sequences, all the KV strains could also be further divided into KV1 and KV2 subgenotypes, and the VP1 gene sequences of the DHAV-3 strains in KV genotype shared $91.8 \%-100 \%$ nucleotide and 93.3\%-100\% amino acid sequence homology with each other (Table 4). All Korean strains were clustered into KV1, while B63 strain and all Vietnamese strains were clustered into KV2. The VP1 gene sequences of the DHAV-3 strains between $\mathrm{CH}$ and KV genotypes shared only 90.0\%-95.4\% nucleotide similarity and $90.0 \%-94.6 \%$ amino acid similarity with each other (Table 4).

The amino acids alignment showed that there were 10 variable amino acid residues highly conserved within genotypes or subgenotypes, and the 10 mutation points existed 
(a)

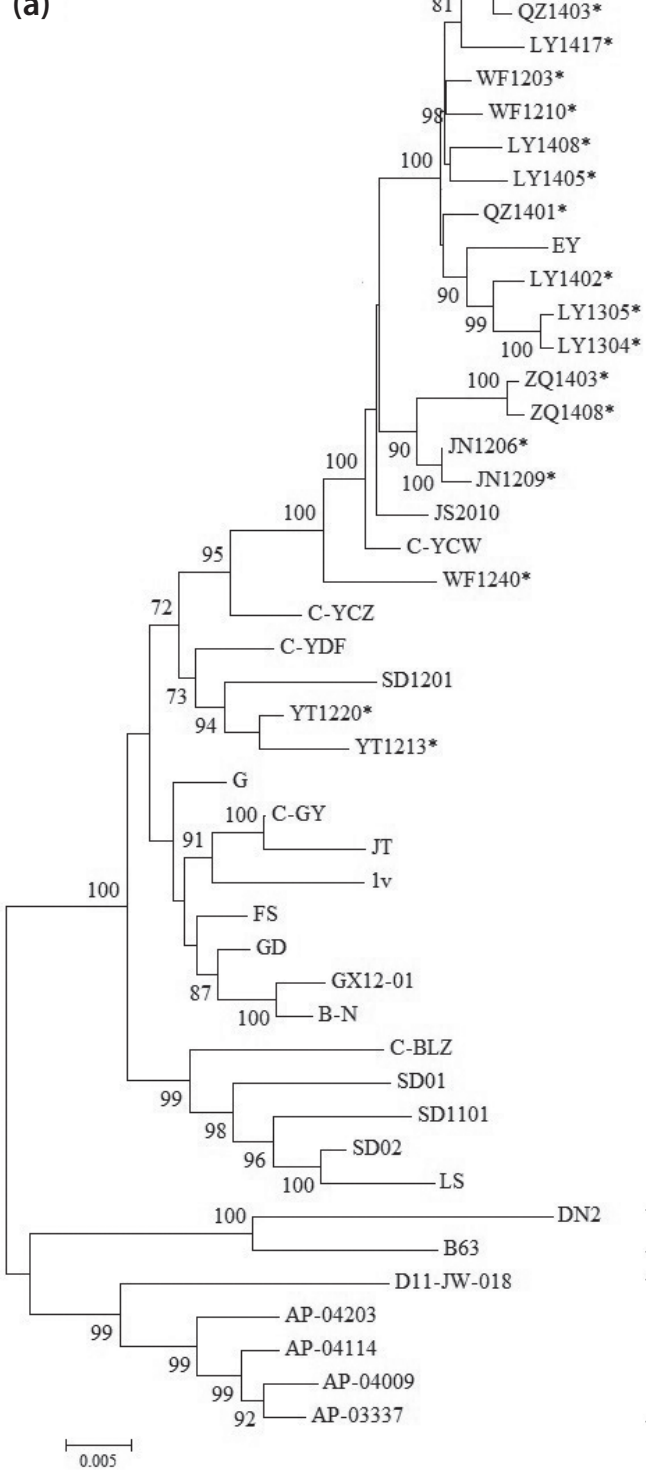

(b)

$\mathrm{CH}$

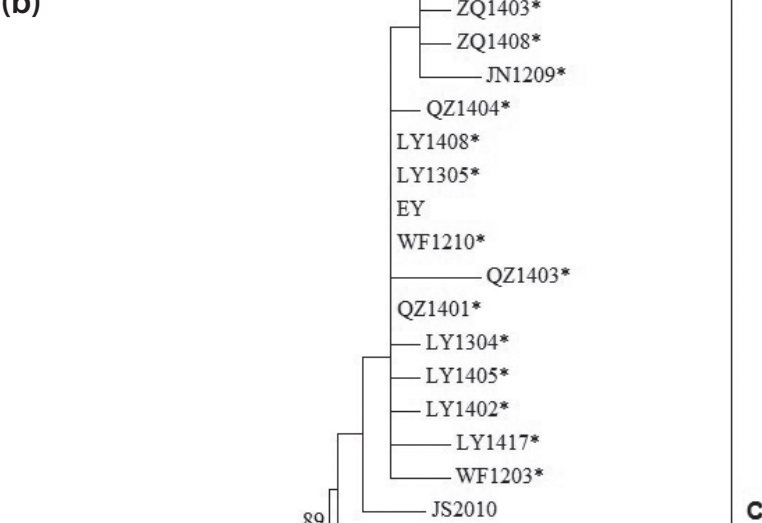

$\mathrm{CH}$

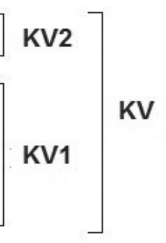

KV

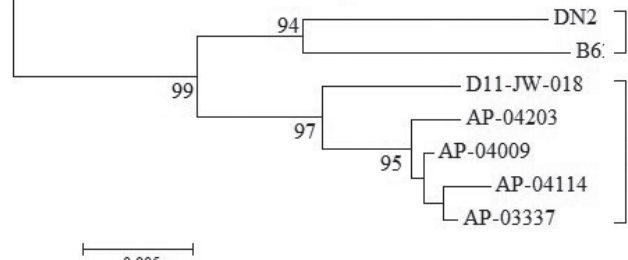

KV2

Fig. 2

Phylogenetic (neighbor-joining) trees based on DHAV-3 P1 nucleotide sequences (a) and amino acid sequences (b)

The values at the forks indicate the percentage of trees, in which this grouping occurred after bootstrapping the data (1000 replicates; shown only when $>70 \%)$. The scale bar shows the number of substitutions per base. Isolates in this study were marked with asterisks $\left({ }^{*}\right)$.

Table 3. The nucleotide and amino acid sequence identity of P1 protein between DHAV-3 strains of different genotype and subgenotype

\begin{tabular}{lccccccc}
\hline \multirow{2}{*}{ Genotype or subgenotype } & \multicolumn{3}{c}{ Nucleotide similarity (\%) } & & \multicolumn{3}{c}{ Amino acid similarity (\%) } \\
\cline { 2 - 3 } \cline { 7 - 9 } & CH & KV1 & KV2 & & CH & KV1 & KV2 \\
\hline CH & $94.7-99.8$ & $92.9-96.1$ & $91.9-94.7$ & & $95.2-100$ & $95.4-97.1$ & $95.2-96.9$ \\
KV1 & $92.9-96.1$ & $96.4-99.3$ & $93.4-96.3$ & & $95.4-97.1$ & $98.5-99.9$ & $97.0-98.9$ \\
KV2 & $91.9-94.7$ & $93.4-96.3$ & 96.3 & & $95.2-96.9$ & $97.0-98.9$ & 97.1 \\
\hline
\end{tabular}


(a)
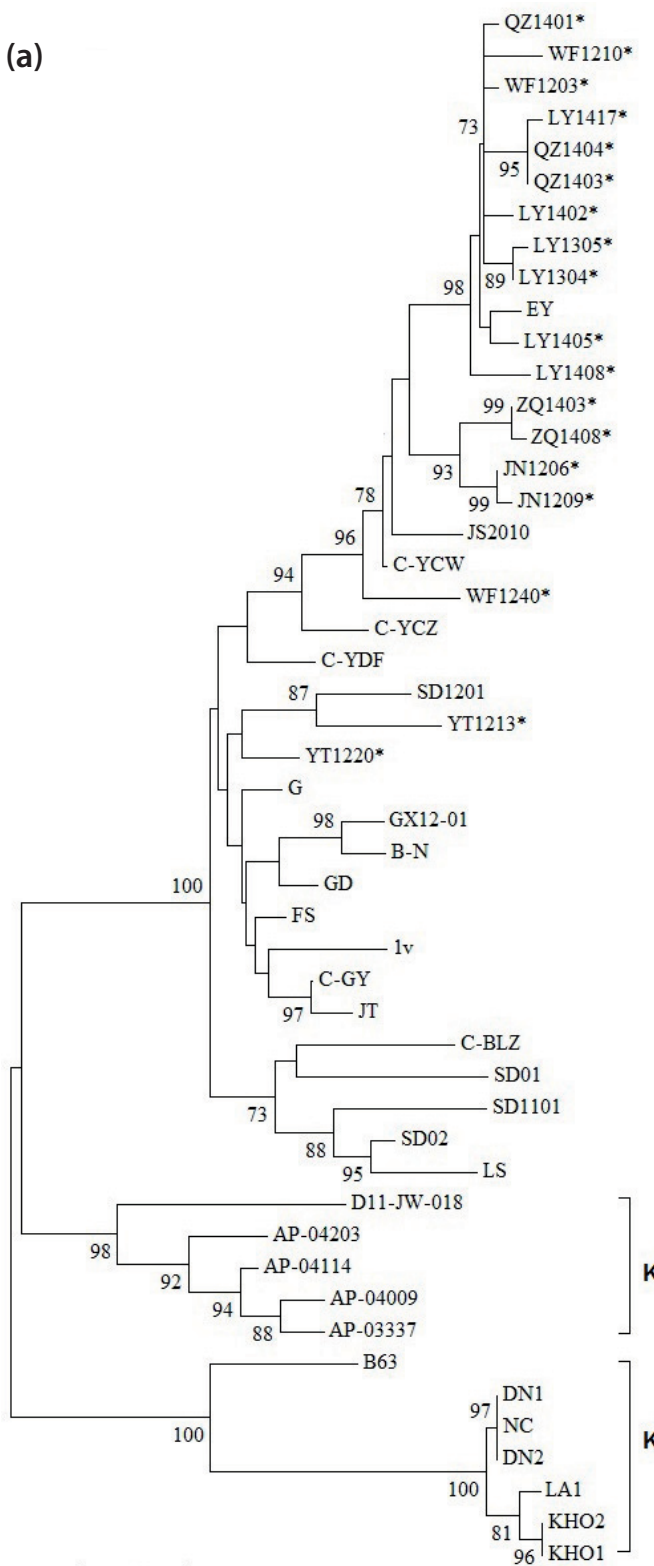

0.01

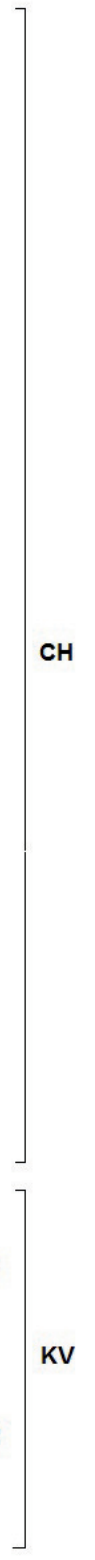

(b)

$\mathrm{CH}$

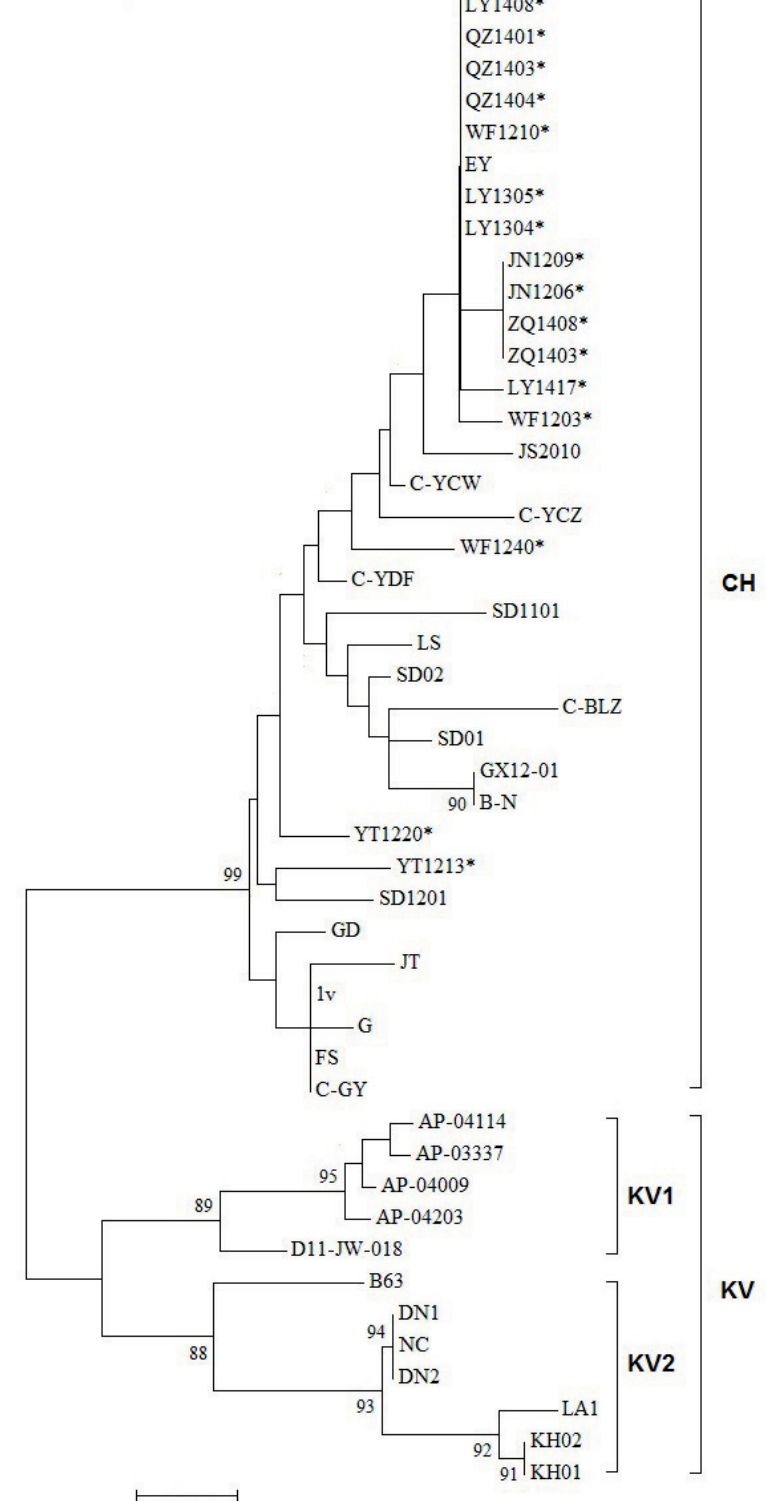

Fig. 3

Phylogenetic (neighbor-joining) trees based on DHAV-3 VP1 nucleotide sequences (a) and amino acid sequences (b)

The values at the forks indicate the percentage of trees, in which this grouping occurred after bootstrapping the data (1000 replicates; shown only when $>70 \%)$. The scale bar shows the number of substitutions per base. Isolates in this study were marked with asterisks $\left(^{*}\right)$.

Table 4. The nucleotide and amino acid sequence identity of VP1 protein between DHAV-3 strains of different genotype and subgenotype

\begin{tabular}{lccccccc}
\hline \multirow{2}{*}{ Genotype or subgenotype } & \multicolumn{3}{c}{ Nucleotide similarity (\%) } & & \multicolumn{3}{c}{ Amino acid similarity (\%) } \\
\cline { 2 - 4 } \cline { 5 - 7 } & CH & KV1 & KV2 & & CH & KV1 \\
\hline CH & $93.9-100$ & $91.9-95.4$ & $90.0-95.4$ & & $95.4-100$ & $91.7-94.6$ & $90-94.6$ \\
KV1 & $91.9-95.4$ & $95.7-99.2$ & $91.8-94.2$ & & $91.7-94.6$ & $97.1-99.6$ & $93.3-99.6$ \\
KV2 & $90.0-95.4$ & $91.8-94.2$ & $95.4-100$ & & $90-94.6$ & $93.3-99.6$ & $95.4-100$ \\
\hline
\end{tabular}


Table 5. Ten variable amino acid residues highly conserved within genotypes or subgenotypes in DHAV-3 P1 protein

\begin{tabular}{|c|c|c|c|c|}
\hline \multirow{2}{*}{ Amino acid regions of $P 1$} & \multirow{2}{*}{$\begin{array}{c}\text { Amino acid variation } \\
\text { points }\end{array}$} & \multirow{2}{*}{$\mathrm{CH}(37)^{\star}$} & \multicolumn{2}{|c|}{$\mathrm{KV}(12)$} \\
\hline & & & KV1(5) & KV2(7) \\
\hline \multirow{2}{*}{ VP0 (1-256) } & 164 & $\mathrm{Y}(36) / \mathrm{N}(1)$ & $\mathrm{F}(5)$ & $\mathrm{F}(2)$ \\
\hline & 210 & $\mathrm{D}(37)$ & $\mathrm{E}(5)$ & $\mathrm{E}(2)$ \\
\hline \multirow{2}{*}{ VP3 (257-493) } & 485 & $\mathrm{~A}(20) / \mathrm{G}(17)$ & $\mathrm{N}(5)$ & $\mathrm{N}(2)$ \\
\hline & 492 & $\mathrm{~N}(37)$ & $\mathrm{D}(5)$ & $\mathrm{D}(2)$ \\
\hline \multirow{6}{*}{ VP1 (494-733) } & 528 & $\mathrm{~L}(37)$ & $\mathrm{F}(5)$ & $\mathrm{F}(7)$ \\
\hline & 590 & $\mathrm{M}(37)$ & $\mathrm{T}(5)$ & $\mathrm{T}(7)$ \\
\hline & 616 & $\mathrm{~N}(37)$ & $S(5)$ & $S(7)$ \\
\hline & 671 & $\mathrm{P}(37)$ & $S(5)$ & $\mathrm{S}(5) / \mathrm{T}(2)$ \\
\hline & 676 & $\mathrm{H}(37)$ & $\mathrm{P}(5)$ & $\mathrm{P}(7)$ \\
\hline & 712 & $\mathrm{H}(36) / \mathrm{R}(1)$ & $\mathrm{L}(5)$ & $\mathrm{Y}(7)$ \\
\hline
\end{tabular}

not only in VP1 but also in VP0 and VP3 (Table 5), which indicated that the genetic variation of $\mathrm{P} 1$ proteins was consistent with their genotypes.

\section{Discussion}

In this study, we detected DHAV-1, DHAV-3 and DAstV-1 in clinical liver specimens from 126 different duckling flocks in Shandong province of China during 2012 to 2014. Among the 482 clinical liver samples, 225 (46.7\%) samples were positive for DHAV-1 infection, 311 (64.5\%) samples were positive for DHAV-3 infection, and 49 (10.2\%) were positive for DAstV-1 infection (Table 2). Otherwise, of the 126 duckling flocks, 65 (51.6\%) were positive for DHAV-1 infection, $92(73.0 \%)$ were positive for DHAV-3 infection, and 29 (23.0\%) were positive for DAstV-1 infection. The results showed that DHAV-3 was the most predominant DHV serotype in Shandong province of China in recent years, which was consistent with our previous studies (Chen et al., 2013, 2014; Lin et al., 2016).

As has been shown in other members of the Picornaviridae, such as foot and mouth disease virus (FMDV) and encephalomyocarditis virus (EMCV), VP1 is considered as the most abundant external capsid protein and contains the primary neutralization epitope (Costa-Mattioli et al., 2002; Kim et al., 2006). Earlier studies suggested that the expressed FMDV capsid precursor protein could be folded properly to maintain the functional discontinuous epitopes (Saiz et al., 1994; Biswal et al., 2015). Analysis of the capsid proteins of DHAV indicated that some conserved functions might be performed by different capsid proteins in DHAV (Ding and Zhang, 2007). In DHAVs, VP1 is the most external and dominant of viral surface proteins and has the highest genetic diversity amongst different isolates (Kim et al., 2006, Tseng et al., 2006; Ding and Zhang, 2007; Gao et al., 2012; Xu et al., 2013).
The genetic variation and molecular evolution of DHAV-3 VP1 have been studied (Xu et al., 2013; Ma et al., 2015). Although the rate of nucleotide substitution for DHAV-3 VP1 genes was about three times faster than that for DHAV-1 VP1 genes, no detectable changes were found in viral neutralization properties within the same serotype (Ma et al., 2015). In this study, we sequenced and analyzed the complete P1 genes of 18 DHAV-3 strains isolated from Shandong province of China from 2012 to 2014 . The results showed that the P1 genes of all DHAV-3 strains shared $91.9 \%-99.8 \%$ nucleotide similarity and $95.2 \%-100 \%$ amino acid similarity with each other. Based on the P1 sequences of the 44 DHAV- 3 strains and VP1 sequences of the 49 DHAV- 3 strains, the phylogenetic trees indicated that the genotyping of DHAV-3 strains presented a distinct geographical distribution. Except B63 strain, all Chinese strains isolated from different host species (duck or goose) at different time were classed into the $\mathrm{CH}$ genotype, while all Korean and Vietnamese strains belonged to the KV genotype (Fig. 2 and 3). The amino acids alignment showed that ten variable amino acid residues existing in the VP0, VP3 and VP1 were highly conserved within genotypes or subgenotypes (Table 3), which indicated that the ten variable amino acid residues were possibly the geographic molecular markers, and were beneficial in further research on the epidemiological investigation of DHAV-3.

Interestingly, as the only Chinese strain divided into KV genotype, the B63, was isolated in China in 2008, but until now, its source still remained unclear. It gives us the indication that we should pay more attention to detection of the genetic variations of DHAV-3. Recently, DHAV-3 was detected in geese, which showed new epidemiological characteristics of DHAV (Liu et al., 2011). The three DHAV-3 strains (JT, EY and LA1) isolated from geese in China and Vietnam sharing high sequence identity with the strains isolated from ducks reminded us to prevent the cross-infection between duck and goose in the control of duck viral hepatitis. 
According to the amino acid alignment, different from the conserved SGD (Arg-Gly-Asp) motif of DHAV-1, an identical QSD motif (amino acids 689-691) existed in the HVR of all 49 DHAV-3 strains (Fig. 1). Previous research of picornaviruses suggested that the conservative RGD (Arg-Gly-Asp) motif played a critical role in viral infectivity and the mutations at the motif had significant effect on viral growth (Rossmann et al., 1985; Boonyakiat et al., 2001; Rieder et al., 2005). In our recent study we showed that there were no significant differences in the viral load in the same organ regardless whether the ducklings were single-infected of co-infected by DHAV-1 and DHAV-3. This indicates that the co-infection of the two viruses had no effect on the in vivo viral loads (Lin et al., 2016). More studies should be done to examine whether the QSD motif in DHAV-3 and the SGD motif in DHAV-1 interacted with different cell receptors in the infected ducklings.

Acknowledgements. This study was funded by grants from National Key R\&D Program (2016YFD0500800), A Project of Shandong Province Agriculture Major Applied Technique Innovation, China and Shandong Modern Agricultural Technology \& Industry System, China (SDAIT-13-011-15).

\section{References}

Biswal JK, Bisht P, Mohapatra JK, Ranjan R, Sanyal A, Pattnaik B (2015): Application of a recombinant capsid polyprotein (P1) expressed in a prokaryotic system to detect antibodies against foot-and-mouth disease virus serotype O. J. Virol. Methods 215-216, 45-51. https://doi.org/10.1016/j. jviromet.2015.02.008

Boonyakiat Y, Hughes PJ, Ghazi F, Stanway G (2001): Arginineglycine-aspartic acid motif is critical for human parechovirus 1 entry. J. Virol. 75, 10000-10004. https://doi. org/10.1128/JVI.75.20.10000-10004.2001

Chen LL, Xu Q, Zhang RH, Yang L, Li JX, Xie ZJ, Zhu YL, Jiang SJ, Si XK (2013): Improved duplex RT-PCR assay for differential diagnosis of mixed infection of duck hepatitis A virus type 1 and type 3 in ducklings. J. Virol. Methods 192, 12-17. https://doi.org/10.1016/j.jviromet.2013.04.012

Chen L, Ma M, Zhang R, Xu Q, Si X, Wang Y, Xie Z, Jiang S (2014): Simultaneous detection of duck hepatitis A virus types 1 and 3, and of duck astrovirus type 1, by multiplex RTPCR. Virol. Sin. 29, 196-198. https://doi.org/10.1007/ s12250-014-3444-8

Costa-Mattioli M, Cristina J, Romero H, Perez-Bercof R, Casane D, Colina R, Garcia L, Vega I, Glikman G, Romanowsky V, Castello A, Nicand E, Gassin M, Billaudel S, Ferre V (2002): Molecular evolution of hepatitis A virus: a new classification based on the complete VP1 protein. J. Virol. 76, 9516-9525. https://doi.org/10.1128/JVI.76.18.95169525.2002

Ding C, Zhang D (2007): Molecular analysis of duck hepatitis virus type 1. Virology 361, 9-17. https://doi.org/10.1016/j. virol.2007.01.007
Fu Y, Pan M, Wang X, Xu Y, Yang H, Zhang D (2008): Molecular detection and typing of duck hepatitis A virus directly from clinical specimens. Vet. Microbiol. 131, 247-257. https://doi.org/10.1016/j.vetmic.2008.03.011

Gao J, Chen J, Si X, Xie Z, Zhu Y, Zhang X, Wang S, Jiang S (2012): Genetic variation of the VP1 gene of the virulent duck hepatitis A virus type 1 (DHAV-1) isolates in Shandong province of China. Virol. Sin. 27, 248-253. https://doi. org/10.1007/s12250-012-3255-8

Haider SA, Calnek BW (1979): In vitro isolation, propagation, and characterization of duck hepatitis virus type III. Avian Dis. 23, 715-729. https://doi.org/10.2307/1589748

Johansson S, Niklasson B, Maizel J, Gorbalenya AE, Lindberg AM (2002): Molecular analysis of three Ljungan virus isolates reveals a new, close-to-root lineage of the Picornaviridae with a cluster of two unrelated 2A proteins. J. Virol. 76, 8920-8930. https://doi.org/10.1128/JVI.76.17.8920-8930.2002

Kim MC, Kwon YK, Joh SJ, Lindberg AM, Kwon JH, Kim JH, Kim SJ (2006): Molecular analysis of duck hepatitis virus type 1 reveals a novel lineage close to the genus Parechovirus in the family Picornaviridae. J. Gen. Virol. 87, 3307-3316. https://doi.org/10.1099/vir.0.81804-0

Kim MC, Kwon YK, Joh SJ, Kim SJ, Tolf C, Kim JH, Sung HW, Lindberg AM, Kwon JH (2007): Recent Korean isolates of duck hepatitis virus reveal the presence of a new genoand serotype when compared to duck hepatitis virus type 1 type strains. Arch. Virol. 152, 2059-2072. https://doi. org/10.1007/s00705-007-1023-0

Lin SL, Cong RC, Zhang RH, Chen JH, Xia LL, Xie ZJ, Wang Y, Zhu YL, Jiang SJ (2016): Circulation and in vivo distribution of duck hepatitis A virus types 1 and 3 in infected ducklings. Arch. Virol. 161, 405-416. https://doi.org/10.1007/ s00705-015-2648-Z

Liu M, Fanyi M, Li XJ, Zhang Z, Liu S, Zhang Y (2011): Goose haemorrhagic hepatitis caused by a new subtype duck hepatitis type 1 virus. Vet. Microbiol. 152, 280-283. https://doi.org/10.1016/j.vetmic.2011.05.015

Ma X, Sheng Z, Huang B, Qi L, Li Y, Yu K, Liu C, Qin Z, Wang D, Song M, Li F (2015): Molecular Evolution and Genetic Analysis of the Major Capsid Protein VP1 of Duck Hepatitis A Viruses: Implications for Antigenic Stability. PLoS One 10, e0132982. https://doi.org/10.1371/journal.pone.0132982

Rieder E, Henry T, Duque H, Baxt B (2005): Analysis of a foot-andmouth disease virus type A24 isolate containing an SGD receptor recognition site in vitro and its pathogenesis in cattle. J. Virol. 79, 12989-12998. https://doi.org/10.1128/ JVI.79.20.12989-12998.2005

Rossmann MG, Arnold E, Erickson JW, Frankenberger EA, Griffith JP, Hecht HJ, Johnson JE, Kamer G, Luo M, Mosser AG, Rueckert RR Sherry B Vriend G (1985): Structure of a human common cold virus and functional relationship to other picornaviruses. Nature 317, 145-153. https://doi. org/10.1038/317145a0

Sáiz JC, Cairó J, Medina M, Zuidema D, Abrams C, Belsham GJ, Domingo E, Vlak JM (1994): Unprocessed foot-andmouth disease virus capsid precursor displays discontinuous epitopes involved in viral neutralization. J. Virol. $68,4557-4564$. 
Soliman M, Alfajaro MM, Lee MH, Jeong YJ, Kim DS, Son KY, Kwon J, Choi JS, Lim JS, Lee TU, Cho KO, Kang MI (2015): The prevalence of duck hepatitis A virus types 1 and 3 on Korean duck farms. Arch. Virol. 160, 493-498. https://doi.org/10.1007/s00705-014-2264-3

Tamura K, Stecher G, Peterson D, Filipski A, Kumar S (2013): MEGA6: Molecular Evolutionary Genetics Analysis version 6.0. Mol. Biol. Evol. 30, 2725-2729. https://doi. org $/ 10.1093 / \mathrm{molbev} / \mathrm{mst} 197$

Toth TE (1969): Studies of an agent causing mortality among ducklings immune to duck virus hepatitis. Avian Dis. 13, 834-846. https://doi.org/10.2307/1588590

Tseng CH, Knowles NJ, Tsai HJ (2007): Molecular analysis of duck hepatitis virus type 1 indicates that it should be assigned to a new genus. Virus Res. 123, 190-203. https://doi. org/10.1016/j.virusres.2006.09.007
Tseng CH, Tsai HJ (2007): Molecular characterization of a new serotype of duck hepatitis virus. Virus Res. 126, 19-31. https://doi.org/10.1016/j.virusres.2007.01.012

Woolcock PR (2003): Duck hepatitis. In Saif YM, Barnes HJ, Glisson JR, Fadly AM, McDougald LR, Swayne DE (Eds): Diseases of Poultry. Eleventh ed. Iowa State Press, Ames, IA, pp. 343-354.

Xu Q, Chen LL, Zhang RH, Yang L, Xie ZJ, Zhu YL, Jiang SJ, Si XK (2013): Sequence analysis of VP1 gene of the duck hepatitis A virus type 3 strains isolated from Shandong Province of China in 2012. Bing Du Xue Bao 29, 522-528 (in Chinese).

Xu Q, Zhang R, Chen L, Yang L, Li J, Dou P, Wang H, Xie Z, Wang Y, Jiang S (2012): Complete genome sequence of a duck hepatitis a virus type 3 identified in eastern China. J. Virol. 86, 13848. https://doi.org/10.1128/JVI.02651-12 